\title{
Effect and status of SARS-CoV-2 pandemic in India
}

\author{
Anjali Gupta ${ }^{1}$ and Sachin Kumar ${ }^{1}$ \\ ${ }^{1}$ Indian Institute of Technology Guwahati
}

April 28, 2020

\section{Outbreak Alerts}

Novel coronavirus, also known as SARS-CoV-2 linked pandemic, started from Wuhan China during December 2019 (Guo et al., 2020 ). Transmission from the original place took place long before the World Health Organization (WHO) declared it a public emergency on 30th January 2020. As of 12th April, WHO has confirmed 1,614,951 live infected cases and 99,887 deaths in around 200 countries. In India, the first coronavirus positive case was reported from Kerala on 30th January 2020 (Ministry of Health and Family Welfare, 2020d ). Later, the positive cases in India came from Delhi dweller who returned from Italy and a man from Telangana who returned from Dubai. After that, some positive cases were detected within Italian tourists and their tour guide in Rajasthan. Overall, the virus spread in the country has primarily occurred due to foreign travelers or Indian travelers coming from abroad.

Currently, India is standing up in the initial stage of community transmission. As per 30th March 2020 Ministry of Health and Family Welfare, Government of India has announced 1224 COVID-19 cases from all over the 27 states and union territories with maximum from Maharashtra (192 cases) and Kerala (202 cases) (Ministry of Health and Family Welfare, 2020a ). The trend of COVID-19 in India has marked slow increase with the primary reproduction number R0 value 1.5 as compared to China (R0 value 2.3), Italy (R0 value 2.34) and Iran (R0 value 2.73) during their 3rd week from the onset of initial SARS CoV-2 positive cases (Cereda et al., 2020; Mandal et al., 2020; Zhao et al., 2020 ). On average, each patient transmits the infection to an additional 2.2 individuals. Based on data from the first cases in Wuhan and investigations by the China CDC, the incubation time can be from 3 to 7 days and up to 2 weeks as the longest time (95\% CI, 9.2 to 18) (Singhal, 2020 ). As per the WHO 70th situation report, most of the European regions like Italy, Spain, France are dealing with up to $11 \%, 7.8 \%, 6.2 \%$, of case-fatality rate, even more than China (4\%)(Onder, Rezza, \& Brusaferro, 2020; World Health Organization, 2020 ). Globally, the case-fatality rate is around 2-3\% however, severely affected patients may die due to excessive alveolar damage, which leads to progressive respiratory failure as evident from many countries, including Italy and China. SARS-CoV-2 is the seventh coronavirus known to infect humans. Along with SARS-CoV, MERS-CoV, and SARS-CoV-2 severe symptoms causing epidemics whereas HKU1, NL63, OC43 and 229E are associated with mild symptoms (Li et al., 2020; Yang et al., 2020 ).

For now, more than 500 whole-genome sequences of different strains of SARS-CoV are reported. Out of these, around 160 isolates have been reported in recent outbreaks mostly from China, Italy, Iran, the USA, Japan, Australia, France, and two from India as well. Two known Indian isolates SARS-CoV2/166/human/2020/IND (GeneBank: MT050493.1) of 29,851 bp and SARS-CoV-2/29/human/2020/IND (GenBank: MT012098.1) of 29,854 bp are deposited by National Institute of Virology, Pune, Maharashtra. Although both strains are isolated from swabs of infected patients from Kerala, the sequencing of more isolates should be carried out regional wise across major infected areas. Further, systematic gene-level mutational analysis of local strains will enable researchers to identify several unique features of the SARS-CoV-2 genome and the development of more efficient therapeutics and vaccines. 
Several properties of SARS-CoV-2 make its prevention difficult, namely, non-specific features of the disease, the infectivity even before the onset of symptoms, transmission from asymptomatic people, and long incubation period. Hence, the Indian Government has projected proactive measures to inhibit the spread of SARS-CoV-2 from initial careers coming from abroad to the local community. Implementation of 21 days lockdown all over the country has greatly helped to flatten the logarithm spread within the community (Government of India, 2020) . Meanwhile, to meet the requirement of personal protection equipment, masks and ventilators, and other essential items, the government is allowing domestic companies and manufacturers clearing quality tests to come-up with more supplies. The supply of N95 masks has been ramped up to 1,00,000/day by local manufactures mostly and DRDO (Ministry of Health and Family Welfare, 2020b ).

Moreover, total government laboratories approved and supported by Indian Council of Medical Research (ICMR) to provide diagnostic kit for SARS-CoV-2 testing has been increased to 123 all over the country(Indian Council of Medical Research, 2020b). The government-led awareness programs based on WHO, CDC, and FAO recommendation on COVID-19 has been enforced to all the states (Ministry of Health and Family Welfare, 2020c ). Besides, the state government issued instructions on the closing of all schools and colleges, malls, and any form of the public gathering. As per reports, a widely-used drug Chloroquine, has recently been reported as a potential broad-spectrum antiviral drug. It blocks the virus infection by increasing endosomal $\mathrm{pH}$ required for virus/cell fusion, as well as to interfere with the glycosylation of cellular receptors of SARS-CoV (Savarino, Di Trani, Donatelli, Cauda, \& Cassone, 2006; Wang et al., 2020; Yan et al., 2013). Indian government has allowed restricted use of Chloroquine among doctors and other staff members coming in direct contact with severe patients to avoid transmission (Indian Council of Medical Research, 2020a ). Besides, the Central Drugs Standard Control Organization approved constricted public health use of lopinavir/ritonavir combination amongst symptomatic COVID-19 patients(Bhatnagar et al., 2020 ).

\section{Conflict of Interest}

The author declares no conflict of interest.

\section{Data Availability Statement}

Data sharing is not applicable to this article as no new data were created or analyzed in this study.

\section{References}

Bhatnagar, T., Murhekar, M. V., Soneja, M., Gupta, N., Giri, S., Wig, N., \& Gangakhedkar, R. (2020). Lopinavir/ritonavir combination therapy amongst symptomatic coronavirus disease 2019 patients in India: Protocol for restricted public health emergency use. Indian J Med Res . doi:10.4103/ijmr.IJMR_502_20

Cereda, D., Tirani, M., Rovida, F., Demicheli, V., Ajelli, M., Poletti, P., . . . Merler, S. (2020). The early phase of the COVID-19 outbreak in Lombardy, Italy. Retrieved from arXiv:2003.09320 [q-bio.PE]

Government of India. (2020). Government of India issues Orders prescribing lockdown for containment of COVID19 Epidemic in the country [Press release]. Retrieved from https://mha.gov.in/sites/default/files/Guidelines.pdf

Guo, Y. R., Cao, Q. D., Hong, Z. S., Tan, Y. Y., Chen, S. D., Jin, H. J., . . . Yan, Y. (2020). The origin, transmission and clinical therapies on coronavirus disease 2019 (COVID-19) outbreak - an update on the status. Mil Med Res, 7 (1), 11. doi:10.1186/s40779-020-00240-0

Indian Council of Medical Research. (2020a). Recommendation for empiric use of hydroxy-chloroquine for prophylaxis of SARS-CoV-2 infection [Press release]. Retrieved from https://icmr.nic.in/sites/default/files/upload_documents/HCQ_Recommendation_22March_final_MM.pdf

Indian Council of Medical Research. (2020b). Total Government Laboratories Approved and Supported (provided diagnostic kits or reagents) by ICMR 123: [Press release]. Retrieved from https://icmr.nic.in/node/39071 
Li, J. Y., You, Z., Wang, Q., Zhou, Z. J., Qiu, Y., Luo, R., \& Ge, X. Y. (2020). The epidemic of 2019-novelcoronavirus (2019-nCoV) pneumonia and insights for emerging infectious diseases in the future.Microbes Infect, 22 (2), 80-85. doi:10.1016/j.micinf.2020.02.002

Mandal, S., Bhatnagar, T., Arinaminpathy, N., Agarwal, A., Chowdhury, A., Murhekar, M., . . . Sarkar, S. (2020). Prudent public health intervention strategies to control the coronavirus disease 2019 transmission in India: A mathematical model-based approach. Indian J Med Res . doi:10.4103/ijmr.IJMR_504_20

Ministry of Health and Family Welfare. (2020a). COVID-19 Situation Board, India . Retrieved from https://www.mohfw.gov.in/

Ministry of Health and Family Welfare. (2020b). COVID-19 Update: Availability of PPE kits, N95 masks and ventilators [Press release]. Retrieved from https://pib.gov.in/newsite/PrintRelease.aspx

Ministry of Health and Family Welfare. (2020c). Update on COVID-19: Advisories and Guidelines for Containment and Prevention [Press release]. Retrieved from https://pib.gov.in/newsite/PrintRelease.aspx

Ministry of Health and Family Welfare. (2020d). Update on Novel Coronavirus: one positive case reported in Kerala . Retrieved from https://pib.gov.in/PressReleasePage.aspx?PRID=1601095

Onder, G., Rezza, G., \& Brusaferro, S. (2020). Case-fatality rate and characteristics of patients dying in relation to COVID-19 in Italy. JAMA . doi:10.1001/jama.2020.4683

Savarino, A., Di Trani, L., Donatelli, I., Cauda, R., \& Cassone, A. (2006). New insights into the antiviral effects of chloroquine.Lancet Infect Dis, 6 (2), 67-69. doi:10.1016/S1473-3099(06)70361-9

Singhal, T. (2020). A Review of Coronavirus Disease-2019 (COVID-19).Indian J Pediatr, 87 (4), 281-286. doi:10.1007/s12098-020-03263-6

Wang, M., Cao, R., Zhang, L., Yang, X., Liu, J., Xu, M., . . . Xiao, G. (2020). Remdesivir and chloroquine effectively inhibit the recently emerged novel coronavirus (2019-nCoV) in vitro. Cell Res, 30 (3), 269-271. doi:10.1038/s41422-020-0282-0

World Health Organization. (2020). Coronavirus disease 2019 (COVID-19) Situation Report - 70 . Retrieved from https://www.who.int/docs/default-source/coronaviruse/situation-reports/20200330-sitrep-70covid-19.pdf?sfvrsn=7e0fe3f8_2

Yan, Y., Zou, Z., Sun, Y., Li, X., Xu, K. F., Wei, Y., . . . Jiang, C. (2013). Anti-malaria drug chloroquine is highly effective in treating avian influenza A H5N1 virus infection in an animal model. Cell Res, 23 (2), 300-302. doi:10.1038/cr.2012.165

Yang, Y., Peng, F., Wang, R., Guan, K., Jiang, T., Xu, G., . . . Chang, C. (2020). The deadly coronaviruses: The 2003 SARS pandemic and the 2020 novel coronavirus epidemic in China. J Autoimmun, 102434. doi:10.1016/j.jaut.2020.102434

Zhao, S., Lin, Q., Ran, J., Musa, S. S., Yang, G., Wang, W., . . . Wang, M. H. (2020). Preliminary estimation of the basic reproduction number of novel coronavirus (2019-nCoV) in China, from 2019 to 2020: A data-driven analysis in the early phase of the outbreak. Int J Infect Dis, 92 , 214-217. doi:10.1016/j.ijid.2020.01.050 